\title{
Five-year survey of medical student attrition in a medical school in Nigeria: a pilot study
}

This article was published in the following Dove Press journal:

Advances in Medical Education and Practice

22 October 2010

Number of times this article has been viewed

\section{Ogugua A Egwu' \\ Godson E Anyanwu² \\ 'Department of Anatomy, Faculty of Basic Medical Sciences, Ebonyi State University, Ebonyi State; ${ }^{2}$ Department of Anatomy, College of Medicine, Faculty of Medical Sciences, University of Nigeria, Enugu State, Nigeria}

Correspondence: GE Anyanwu Department of Anatomy, College of Medicine, Faculty of Medical Sciences, University of Nigeria, Enugu Campus, Enugu State, Nigeria Email anyanwugemeks@yahoo.com
Background: Student attrition represents a waste of career opportunity and, at times, results in a holistic loss of sense of self-worth for the students involved. The aim of this study was to evaluate the nature, causes, and impact of medical student attrition in Nigeria.

Method: A pilot analysis was undertaken using the records of students who failed at medical school as a result of inability to pass the second MBBS examination at Ebonyi State University, Abakaliki, Nigeria, between 2002 and 2007. Some of these students were interviewed using a structured questionnaire.

Results: Data analysis showed that $58(7.8 \%)$ of the students admitted into preclinical class withdrew from their study. Thirty-six $(62.1 \%)$ were males and the rest were females. Thirteen of those withdrawn were interviewed, and $53.8 \%$ of them believed they had poor academic ability, while $15.4 \%$ attributed their withdrawal to family pressure. No record of guidance or counseling session programs was noted for these students either at the point of withdrawal from the faculty and on the choice of a new career path.

Conclusion: As a result of the high attrition rate due to low academic ability, efforts should be made to check students for evidence of this at the point of admission to medicine training. Also, more accommodating teaching programs should be encouraged in faculties to accommodate students with such challenges. Good guidance and counseling programs should be encouraged to handle these inevitable cases of attrition when they occur, to avoid the demoralizing low self-esteem that plagues these individuals for the rest of their lives.

Keywords: medical students, attrition, medical education, Nigeria

\section{Introduction}

Admission to a medical school in Nigeria is a multistaged process requiring both cognitive and noncognitive pretests. These pretests are competitive, with an estimated 100,000 applications made annually to the 30 accredited medical schools in Nigeria. The requirements for admission are structured to identify the best candidates. These requirements include a complete "O" level certificate with a minimum of credit pass in the three basic sciences (biology, chemistry, and physics), English and mathematics, passing of the university matriculation examination, and scoring above the cutoff mark for medical school. This is organized by the Joint Admissions and Matriculations Board. Finally, the candidates sit the post-university matriculation examination, which is organized by the individual schools to admit the number of students approved by the National Universities Commission for the institution. These selection processes favor candidates who are well grounded in the basic sciences. 
When these criteria are met, the training course becomes a hurdle that must be overcome to obtain the highly esteemed medical training certificate, especially the second MBBS (Bachelor of Medicine, Bachelor of Surgery) professional examination, which is seen as the rate-limiting step in medical training. It involves the basic medical sciences, ie, anatomy, biochemistry, and physiology. This constitutes the peak of preclinical training, for which success in the examination guarantees clinical training. The second MBBS examination is taken at the end of the second semester of the third year of the student's academic training. This period provides for a minimum duration of 18 months of training in the basic medical sciences. The remaining two and half years are dedicated to training in pathology, pharmacology, pediatrics, community medicine, medicine, obstetrics and gynecology, and surgery. It is at the second MBBS stage of training and examination that the attrition rate peaks. Attrition is defined as the number of students leaving the faculty without graduating. ${ }^{1}$ These withdrawals at the second MBBS professional examination occur following failure to pass the three core subjects after two attempts, or scoring below $40 \%$ in the three basic medical courses on the first attempt. When either of these occur, the students involved are expelled from medical training. As a result, they are traumatized, and almost every aspect of their lives is negatively affected. According to Simpson and Budd, ${ }^{2}$ each student lost from a medical course represents a waste of a career opportunity, with emotional trauma and uncertainty for the student and his or her family and friends. Psychologically, it also represents a holistic loss of sense of worth on the part of the students and often the prospect of forging ahead with life is remote. Poor academic performance has been implicated in attrition, which may be influenced by several factors, including psychosocial characteristics, ${ }^{3}$ critical thinking skills, ${ }^{4}$ parental income,${ }^{5}$ age of student, ${ }^{6}$ and environmental conditions.

Jonas and $\mathrm{Etzel}^{7}$ and Crowley et $\mathrm{al}^{8}$ have reported that the attrition rate in US medical schools is about $2 \%$, without taking into consideration students who temporarily withdrew to pursue advanced studies. In the UK, Simpson and $\mathrm{Budd}^{2}$ reported a $14 \%$ attrition rate, whereby $53 \%$ of the leaving students were asked to withdraw for academic reasons, $30 \%$ for personal problems, and $8 \%$ on health grounds (mainly psychologic). In a Saudi Arabian university, Bakhsh ${ }^{1}$ reported a $37.3 \%$ attrition rate, with males being slightly fewer than females. Such data have not been reported in Nigeria, although stress, a well known factor in student underperformance, has been studied by Sofola and
Jeboda. ${ }^{9}$ These causative factors have not been explored in the Nigerian medical school environment.

How do we avoid student losses from medicine as a result of poor academic performance? When they occur, how can they be managed to guide the students to other professional areas? To resolve this problem, the attrition rate must be quantified before remedial action is sought. ${ }^{2}$ Presently, there is a lack of information about the number of students lost and reasons for withdrawal from our medical schools at the various stages of medical training. This pilot survey was carried out to evaluate the extent of the problem of medical student attrition at the second MBBS stage, to examine the causes, and to offer possible solutions.

\section{Methods}

A structured questionnaire was administered to a sample of students who were unable to complete the second MBBS stage of medical training at Ebonyi State University, Abakaliki, Nigeria, in 2002-2007. Topics canvassed in the questionnaire included reasons for withdrawal, the student's present attitude towards having being a medical student and the medical course now that they were outside the system, any desire to go back to the course, and any social and/or psychologic impact of their exit from medical school. Academic records of all the medical students in the faculty within these years were obtained from the Dean's office. Information obtained from the records included total number of students admitted into preclinical training, number of students withdrawn for each academic session at the second MBBS stage, and gender. For each year, consenting withdrawn students were interviewed and possible reasons for their withdrawal noted. The records were studied and percentage withdrawals for each session obtained.

\section{Results}

Table 1 shows that a total of $58(7.8 \%)$ students had been withdrawn in 2002-2007 (five academic sessions), of which $62.1 \%$ were male and $37.9 \%$ were female. Table 2 shows the summary of reasons for withdrawal. Poor academic ability was the most common reason for withdrawal, while family pressure ranked lowest. Their records showed that guidance and counseling programs were not conducted at the point of withdrawal from the faculty. Roommates, friends, and peers were cited as the only people to have offered counsel and encouragement at the time of withdrawal. There were no faculty-based programs to assist in the choice of a new career path or steps taken to avoid further failure in alternative academic programs. 
Table I Students' withdrawal rate at second MBBS stage in a medical school in Nigeria

\begin{tabular}{lllllll}
\hline $\begin{array}{l}\text { Academic } \\
\text { sessions }\end{array}$ & $\begin{array}{l}\text { Candidates } \\
\text { admitted }(\mathbf{n})\end{array}$ & $\begin{array}{l}\text { Withdrawn } \\
(\mathbf{n})\end{array}$ & $\begin{array}{l}\text { Males } \\
\text { withdrawn (n) }\end{array}$ & $\begin{array}{l}\text { Females } \\
\text { withdrawn (n) }\end{array}$ & $\begin{array}{l}\text { Percentage } \\
\text { withdrawn }\end{array}$ & \begin{tabular}{l} 
Interviewed (n) \\
\hline $2002 / 2003$
\end{tabular} \\
\hline 131 & 10 & 4 & 6 & 7.7 & 2 \\
$2003 / 2004$ & 124 & 1 & 1 & - & 0.8 & 1 \\
$2004 / 2005$ & 142 & 8 & 5 & 3 & 5.6 & 2 \\
$2005 / 2006$ & 174 & 25 & 20 & 5 & 13.8 & 5 \\
$2006 / 2007$ & 146 & 14 & 6 & 8 & 8.3 & 3 \\
Total & 736 & 58 & 36 & 22 & 7.8 & 13 \\
\hline
\end{tabular}

\section{Discussion}

In as much as the medical school curriculum is designed to ensure that every graduate is knowledgeable, skillful, and professional, ${ }^{10}$ failure to complete the curriculum should also be properly handled. This is because the concept of failure in medical training and subsequent withdrawal may portend psychologic disaster for the student and family members. It may trigger a stigma that accompanies the individual throughout his/her academic career if proper counseling is not implemented. It also tags the individual with a sense of lack of accomplishment, and represents a psychologic trauma that may be worse than physical disability. This problem is likely to be at its worst in Nigeria where medical students are often coerced by their families to embark on medical training because it is perceived as the most lucrative of the professions, with success guaranteeing food on the table. When students with a good knowledge of basic sciences eventually overcome the entry stage, they become confused if there has been no earlier hint of the difficulties involved in training. At that point it is too late to withdraw voluntarily because they are already called doctors at home. Students then decide to face this battle, regardless of their academic ability.

In this study, $7.8 \%$ of the students admitted to preclinical courses withdrew at the second MBBS stage. This attrition rate can be considered high compared with some US universities that have recorded rates of about $2 \% .{ }^{7,8}$ When compared with Simpson and Budd's ${ }^{2}$ study in a UK university that reported a $14 \%$ attrition rate over a 10 -year period, it appears low, even though the attrition rate in this case spans the entire duration of medical training. When compared with studies

Table 2 Summary of reasons for withdrawal from training at the second MBBS stage

\begin{tabular}{lll}
\hline Reason for withdrawal & Number & Percentage \\
\hline Social distractions & 4 & 30.8 \\
Family pressure/interest & 2 & 15.4 \\
Poor academic ability & 7 & 53.8 \\
\hline
\end{tabular}

by Bakhsh ${ }^{1,11}$ in Saudi Arabia, where attrition rates were 37\% and $20 \%$, respectively, in the different periods, our results appear quite low. Farhadi et $\mathrm{al}^{6}$ reported a $15.34 \%$ attrition rate for an academic course at Lorestan University of Medical Sciences. In their study, they also reported a higher attrition rate for females than for males, which is in contrast with our results showing males had significantly higher attrition rates than females. This may be attributed to the traditional African belief that men are the struggling gender, and so may have a wide range of social and environmental distractions that impact their academic performance.

The majority of the students interviewed believed that poor academic ability was the reason for their removal from medical school. This is often a pointer to reduced self esteem. People with good self-esteem respond less negatively to failure than people with poor self-esteem. This may be because people with good self-esteem are able to overcome the natural tendency to focus on negative thoughts after failure, and instead focus on their strengths. ${ }^{12,13}$ Individuals with low self-esteem downplay the importance of appearing competent to others and associate themselves with failure on an implicit level, ${ }^{14}$ feeling worthless in society, a condition that eternally haunts them, and may lead to psychologic morbidity, which appears to impact adversely on academic performance. ${ }^{15}$ This is because failure at this stage of the training is usually gradual, with some failing up to three times before being asked to leave the faculty. Most times, individuals in this category are people who have seen and continued to perceive failure without being able to reposition themselves for better performance and, hence, their perceived poor academic ability.

Social distractions ranked second on the list of reasons for withdrawal. These distractions may be a reaction to undue stress and reduced mental health arising from academic pressure and excess workload. Studies in UK and US medical schools suggest that up to half of students have symptoms of depression ${ }^{16}$ and poor mental health. ${ }^{17}$ As a result, they tend to incorporate stress-diffusing activities into their daily 
program, and this partially or totally distracts them from their academic activities.

On the issue of family pressure and disinterestedness, some students believed that they had no reason whatsoever to be in medical school, and had been convinced by their families to become doctors. And where there is no interest, there is no learning. Such students were relieved to be asked to leave their training course.

The consequences of attrition cannot be overemphasized. It increases stress levels and promotes a high level of psychosocial morbidity in the academic and social environment. Therefore, attrition and its negative effects in medical schools should be recognized and accommodated in the medical curriculum. All medical schools should have stress intervention programs that identify and monitor distressed and struggling students and give them assistance to prevent development of a pathologic environment that will ultimately affect the economic viability of the country. It has been reported that medical students experience high levels of personal distress, ${ }^{18-20}$ with possible adverse consequences on academic performance, ${ }^{15}$ competency, ${ }^{21}$ and professionalism, ${ }^{22}$ so it is important to incorporate well designed interventional programs in the medical curriculum that will promote better self-awareness and skills for stress management. ${ }^{23}$

More and better paid job opportunities need to be created in ancillary health fields in order to reduce the overzealousness on the part of many parents in Nigeria for their children to become doctors. If this is done, parents will be less inclined to coerce their children to study medicine, and instead encourage them into other related disciplines commensurate with their academic ability and interest. Because low parental income can lead to poor academic performance, the Nigerian government needs to encourage economically disadvantaged but academically suitable students by providing scholarships, to reduce the inevitable social and economic distractions which, in this study, are highlighted as a cause of poor performance and leading to attrition.

Medical schools should establish medical education/ student units to monitor the psychosociocognitive inclinations of their students, and enable appropriate guidance in the next choice of discipline whenever attrition occurs. Efforts should also be put in place at admission to screen for students who may not be able to cope with the rigorous academic challenge of studying medicine. This will help to spare these students from a colossal waste of their time and the low self-esteem that often accompanies failure, as well as afford these students an opportunity to pursue other studies in which they will be able to excel.

\section{Disclosure}

The authors report no conflicts of interest in this work.

\section{References}

1. Bakhsh TM. Attrition rate at a faculty of medicine in Western Saudi Arabia. J KAUA Med Sci. 2004;11:99-104.

2. Simpson KH, Budd K. Medical student attrition: A 10-year survey in one medical school. Med Educ. 1996;30:172-178.

3. Hojat M, Robeson M, Damjanov I, Veloski JJ, Glaser K, Gonella JS. Students' psychosocial characteristics as predictors of academic performance in medical school. Acad Med. 1993;68:635-637.

4. Scott JN, Markert RJ. Relationship between critical thinking skills and success in preclinical courses. Acad Med. 1994;69:920-924.

5. Fadem B, Schuchman M, Simring SS. The relationship between parental income and academic performance of medical students. Acad Med. 1995;70:1142-1144.

6. Farhadi A, Javaheri F, Gholami YB. Effective factors on students' academic attrition in Lorestan University of Medical Sciences. $J$ Med Educ. 2005;8:33-37.

7. Jonas HS, Etzel SI. Undergraduate medical education. JAMA. 1988;260:1063-1071.

8. Crowley AE, Etzel SI, Peterson ES. Undergraduate medical education. JAMA. 1987;258:1013-1020.

9. Sofola OO, Jeboda SO. Perceived sources of stress in Nigerian dental students. Eur J Dent Educ. 2006;10:20-23.

10. Laison Committee on Medical Education. Functions and structure of a medical school. Standards for accreditation of medical education programmes leading to the MD degree (2005) Washington DC. AAMC. Available from: http:/www.lcme.org/pubs.htm\#fands. Accessed 2010 May 15.

11. Bakhsh TM. Analysis of attrition over a 7-year period at the Faculty of Medicine, King Abdulaziz University, Jeddah. JKAUA. Med Sci. 2008; 15:49-57.

12. Dogson PG, Wood JV. Self-esteem and the cognitive accessibility of strengths and weaknesses after failure. J Pers Soc Psychol. 1998; 75:178-197.

13. Brown JD, Dutton KA. The thrill of victory, the complexity of defeat: Self-esteem and people's emotional reactions to success and failure. J Pers Soc Psychol. 1995;68:712-722.

14. Park LE, Crocher J, Kiefer AK. Contingencies of self-worth, academic failure, and goal pursuit. Pers Soc Psychol Bull. 2007;33: $1503-1517$

15. Stewart SM, Lam TH, Betson CL, Wong CM, Wong AM. A prospective analysis of stress and academic performance in the first two years of medical school. Med Educ. 1999;33:243-250.

16. Givens JL, Tijia J. Depressed medical students' use of mental health services and barriers to use. Acad Med. 2002;77:918-921.

17. Moffat KJ, McConnachie A, Ross S, Morrison JM. First year medical student stress and coping in a problem-based learning medical curriculum. Med Educ. 2004;38:482-491.

18. Guthrie E, Black D, Bagalkote H, Shaw C, Campbell M, Creed F. Psychological stress and burnout in medical students: A five-year prospective longitudinal study. J R Soc Med. 1998;91:237-243.

19. Roberts LW, Warner TD, Lyketsos C, Frank E, Ganzini L, Carter D. Perceptions of academic vulnerability associated with personal illness: A study of 1,027 students at nine medical schools. Compr Psychiatry. 2001;42:1-15.

20. Raj SR, Simpson CS, Hopman WM, Singer MA. Health-related quality of life among final-year medical students. CMAJ. 2000;162:509-510. 
21. Hojat M, Gonnella JS, Mangione S, et al. Empathy in medical students as related to academic performance, clinical competence and gender. Med Educ. 2002;36:522-527.

22. Crandall SJ, Volk RJ, Loemker V. Medical students' attitudes toward providing care for the underserved: Are we training socially responsible physicians? JAMA. 1993;269:2519-2523.
23. Lisselotte ND, Mathew RT, Tait DS. Medical students' distress: Causes, consequences and proposed solutions. Mayo Clin Proc. 2005;80: 1613-1622.

\section{Publish your work in this journal}

Advances in Medical Education and Practice is an international, peerreviewed, open access journal that aims to present and publish research on Medical Education covering medical, dental, nursing and allied healthcare professional education. The journal covers undergraduate education, postgraduate training and continuing medical education including emerging trends and innovative models linking education, research, and healthcare services. The manuscript management system is completely online and includes a very quick and fair peer-review system. Visit http://www.dovepress.com/testimonials.php to read real quotes from published authors.

Submit your manuscript here: http://www.dovepress.com/advances-in-medical-education-and-practice-journal 